\title{
Domino donor lymphocyte infusion for secondary poor graft function after HLA-mismatched allogeneic stem cell transplantation between HLA-identical sibling pairs with congenital immunodeficiency
}

Satoru Hamada ${ }^{1}$, Taichi Uehara ${ }^{1}$, Jiro Miyamoto ${ }^{1}$, Shinobu Kiyuna ${ }^{1}$, Tokiko Oshiro ${ }^{1}$, Takeshi Yagi ${ }^{1}$, Shingo Kurokawa ${ }^{1}$, Nobuyuki Hyakuna ${ }^{1}$, and Koichi Nakanishi ${ }^{1}$

${ }^{1}$ Ryukyu Daigaku Igakubu Fuzoku Byoin

September 16, 2020

\begin{abstract}
Poor graft function (PGF) is a major obstacle to successful allogeneic stem cell transplantation after achieving normal bone marrow function. We report a successful treatment of domino DLI for poor graft function in younger brother with hyper IgM syndrome from HLA-identical elder brother with the same disorder with a history of HLA-mismatched unrelated bone marrow transplantation using same donor. Immunological profiling revealed that DLI-induced T-regulatory cells could correct skewed immune responses in the BM microenvironment due to secondary PGF pathogenesis. Immunological tolerized domino DLI can be a new therapeutic option for secondary PGF in HLA-identical sibling pairs with congenital immunodeficiency.
\end{abstract}

\section{Hosted file}

2020_09_13 PBC.pdf available at https://authorea.com/users/359525/articles/481452-dominodonor-lymphocyte-infusion-for-secondary-poor-graft-function-after-hla-mismatchedallogeneic-stem-cell-transplantation-between-hla-identical-sibling-pairs-withcongenital-immunodeficiency 
A
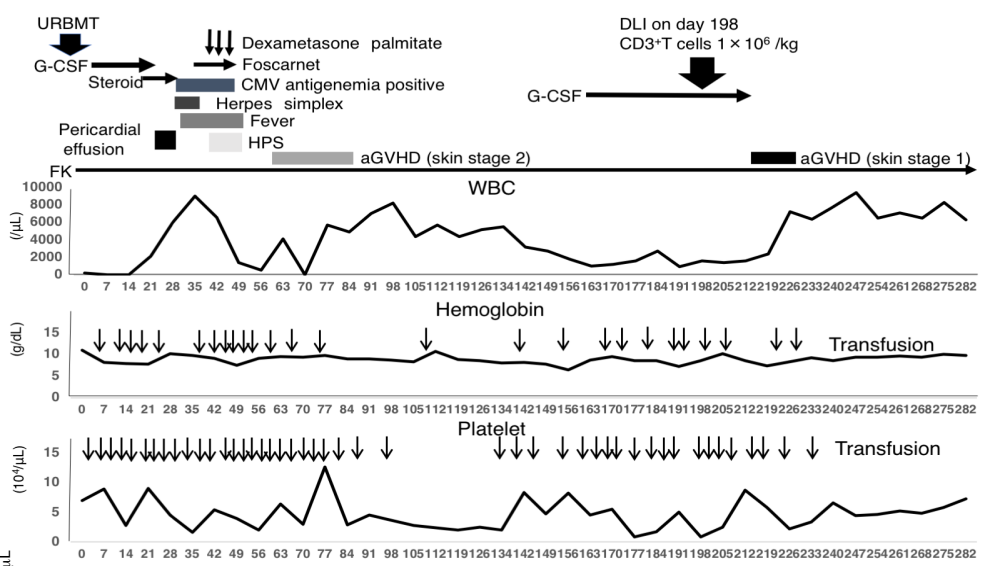

B $\doteq 00714212835424956637077849198105112119126134142149156163170177184191198205212219226233240247254261268275282$

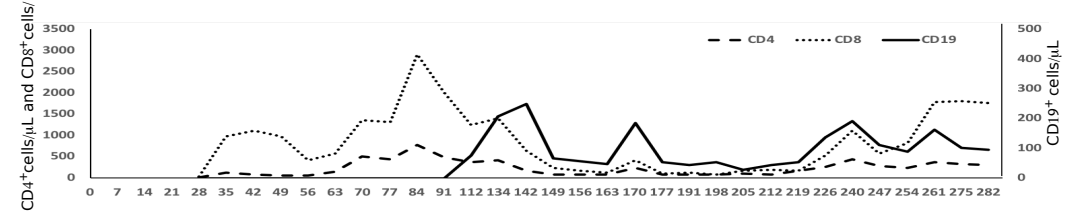



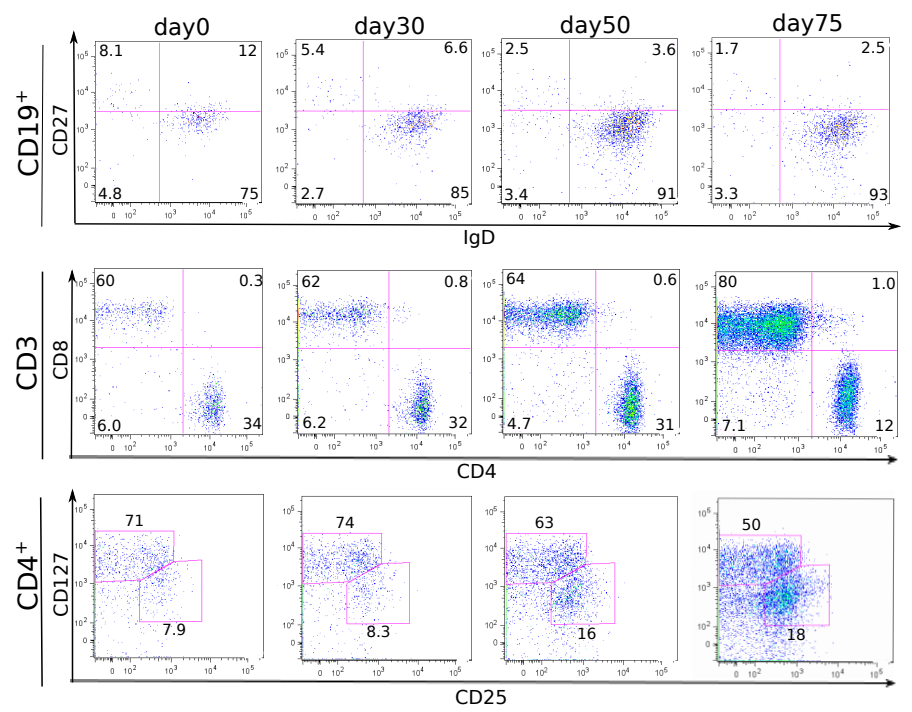